\title{
Factors Affecting School Administrators' Choices in Adopting ICT Tools in Schools - The Case of Malaysian Schools
}

\author{
Termit Kaur Ranjit Singh ${ }^{1} \&$ Kalaivani Muniandi ${ }^{1}$ \\ ${ }^{1}$ School of Educational Studies, Universiti Sains Malaysia, Malaysia \\ Correspondence: Termit Kaur Ranjit Singh, School of Educational Studies, Universiti Sains Malaysia, 11800 \\ Minden, Malaysia. Tel: 604-653-3760. E-mail: termitk@usm.my
}

Received: April 5, 2012 Accepted: April 16, 2012 Online Published: June 15, 2012

doi:10.5539/ies.v5n4p21 URL: http://dx.doi.org/10.5539/ies.v5n4p21

The research is financed by (Sponsoring information): Universiti Sains Malaysia, Malaysia

\begin{abstract}
The Malaysian Government has introduced various initiatives to facilitate the greater adoption and diffusion of ICT to improve capacities in the education system. Due to the extensive investment, schools are expected to utilize and integrate ICTs in administrative tasks, teaching and learning and general running of schools. This study was set out to examine the various factors that influence the use of ICT tools by the school administrators, to identify the process used to select adequate and suitable hardware and software to be utilized in schools and to identify the barriers to technology integration. The findings show the factors that influence the use of ICT tools in schools are willingness of teachers, high level of knowledge and skills, cooperation among teachers, easier and more effective completion of task, high level of trust and confidence placed on the teachers and importantly the good and regular maintenance of hardware and on-site support. This study also finds that lack of facilities, insufficient time to master and apply knowledge due to heavy teaching hours and attitudes of teachers who are not willing to change are the barriers to technology integration.
\end{abstract}

Keywords: ICT tools, adopting ICT, school administrators

\section{Introduction}

The purpose of this article is to share with readers the findings of a study conducted to investigate the factors that affect the choices of School administrators in adopting ICT Tools in schools in Malaysia. This study investigates the factors that influence the use of ICT tools in Malaysian schools.

The Ministry of Education articulation of ICT in education focused on three main areas (Multimedia Development Corporation, 2005):

- ICT will be used as an enabler to reduce the digital divide between the country's schools by enabling ICT access for all students;

- ICT will be used as teaching and learning tools in education, taught as an independent subject and integrated into others; and

- ICT will be used to enhance efficiency, effectiveness and productivity of management in education.

Malaysia's Vision 2020 policy was formulated in 1991 to ensure the transformation of Malaysia into becoming a fully developed nation by the year 2020. The vision calls for the nation to achieve as self-sufficient industrial, Malaysian centric economy. To cope and maximize the leverage of information age, Malaysian Smart Schools as a learning institution was systematically reinvented in order to improve on the existing teaching and learning as well as the management processes (Multimedia Development Corporation, 2005).

The development plan for ICT in education within the next 10 years aims to intensify the development of ICT infrastructure; expand access to and equity for ICT facilities; expand ICT-based curriculum; improve on the assessment and evaluation systems using ICT; emphasize ICT integration in teaching and learning processes; improve on ICT knowledge and skills among students, teachers and personnel; intensify ICT usage in education management; improve on the management and maintenance of ICT equipment; increase R\&D efforts in ICT; and 
increase cooperation between educational institutions and the community towards expansion of ICT in education (Educational Development Plan for Malaysia (2001-2010), 2001).

The Ninth Malaysian Plan (2006-2010) published on March 31, 2006 is the governing framework for ICT policy in Malaysia (Business Monitor International, 2010). According to the report Malaysia experienced a GDP growth of 6.2 percent per annum from the year 1991 to 2005. The Ninth Malaysia Plan provides a 15-year framework for the development of the knowledge economy. Multiple Information and Communications Technology (ICT) projects that will be considered for implementation during this period are computer labs, smart schools, SchoolNet, IT-based tools for teaching Mathematics and Science in English, and the wireless connection of local area networks (LANs) in schools (Business Monitor International, 2010).

The Malaysian Government has since 1970's introduced various schemes to assist in the wider adoption of ICT to boost capabilities in every field including education (Multimedia Development Cooperation, 2005) and many of the concurrent programmes implemented by the Malaysian government has been dedicated to augmenting educational opportunities and upgrading the national education system to foster national unity, support economic growth and reduce poverty.

The use and integration of ICT in teaching and learning has been a priority in many developing countries and with the understandable worries that failure to do so may create a greater digital divide and disparity between the developed and developing nations.

According to Ng, Miao, and Lee (2006), one of the prerequisite for economic and social development is education and governments of the day are pressured into providing education to all of its citizens irrespective of the availability of various resources. At the same time, globalization and the shift to a 'knowledge-based economy' requires that existing educational institutions develop individuals the ability to transform information into knowledge and to apply that in a dynamic, cross-cultural context and ICT are a means for meeting these twin challenges. Information and Communication Technologies offer both challenges and promises for social and economic development and this is nowhere more apparent than in the world's poorest countries.

\subsection{Background and Objectives of Study}

With such an extensive level of educational initiatives thrown into the Malaysian education scenario how do schools ensure the promise that technology holds for students' achievement is realized? What are the factors or combination of factors that should be in place to support the effective use of technology? The singular and dominant benefits of technology in education are its capacity to support all aspects of the learning process from the classroom to the central office. We know that technologies offer teachers and students opportunities that would otherwise be extremely difficult to realize in classroom contexts. School reformers generally recognize four areas as centrally important to improving student achievement: assessment, information access, collaboration and expression. Educational technologies have been shown to demonstrate particular promise in all four (Benton Foundation, 2002).

The integration of ICT into schools has been a focus of a plethora of policy initiatives by governments worldwide for over twenty years. Tearle (2004) who analyzed ICT integration in three schools in the United Kingdom, came to a similar conclusion. She argues the need for a whole-school vision for ICT use, along with a role for school characteristics, culture and ethos that support change, all coupled with the practical support and the visible involvement of the Principal. Research by Anderson and Dexter (2005) endorses the importance of the Principal in establishing a technology committee and budget, personally using technology, spending time on and budgeting for technology integration, however, they conclude that leadership and planning for ICT integration is more a school than an individual characteristic. As mentioned by Sammons (1999), most study of school effectiveness has shown both primary and secondary leadership to be a key factor.

The availability of the computers both hardware and software is only one element of effective integration of ICT in schools. Already there has emerged a need for educational institutions to ensure that graduates are able to display appropriate levels of information literacy, "the capacity to identify an issue and then to identify, locate and evaluate relevant information in order to engage with it or to solve a problem arising from it" (McCausland, Wache, \& Berk, 1999). Districts and schools struggle with the technical demands of maintaining sophisticated high-speed networks, a task that is much more complex than keeping a stand-alone computer running or fixing a printer that has jammed (Benton Foundation, 2002).

School effectiveness has always been the central issue in Malaysian education system as the sector consumes approximately 33\% of national budget. The Ministry of Education in Malaysia strongly emphasize on instructional 
leadership in Principals by defining the mission of the school and developing a vision for schools (Balsandran, 2006).

This study seeks to identify the factors as well as the climate created by a selected school that ranks high in successful integration of ICT in the curricula and in the general day-to-day running of a school. The case study would be able to identify the strong factors as well as barriers seen by school administrator in the day-to-day running of a secondary school.

This study examines the various factors that influences the choices made by the school administrators as well the reasons why certain ICT usages are adopted and why some are abandoned. The results therefore would allow further research on why some schools are more successful than others in implementing bold projects that allow teachers and students in harnessing the potential of ICT

It is hoped that the findings of this study would identify the factors that influences the decisions made by the Principal and his team of administrators on why certain programs are chosen to improve instructional practices and how a successful management team ensures that a continuous graph of growth is maintained. The findings would also identify barriers that impede the success of integration of ICT and which creates reluctance in teachers to use them. The results and findings if communicated well to the policy makers would allow them to find ways around the barriers and ensure that Principals can become better technology leaders, become better integrators of technology into their schools' classroom teaching and help them to promote conducive environment for the $21^{\text {st }}$ century teaching and learning. The objectives of the study are as stated below:

1) To determine the factors that influences the use of ICT tools by the school administrators.

2) To identify the process used to select adequate and suitable hardware and software to be utilized in school.

3) To identify the barriers to technology integration.

The study therefore seeks to find out the various factors that influence the use of ICT tools by the school administrators. The study also seeks to find out how the school administrators go about determining and selecting hardware and software to be used in school and the barriers that prevent effective deployment of ICT tools in Malaysian schools.

The ICT tools that are discussed extensively in this study are limited to computer and its peripherals including the various local area network and wireless networking used through-out the school as well as the Liquid Crystal Display projectors that are used in tandem during lessons.

\section{Related Literature Review}

The advent of Information and Communication Technology has opened up tremendous access and opportunity to increase and advance in our quest for quality in our education system. It gives its users new way to teach and learn and grow in an unprecedented ways.

Inappropriate planning, lack of training, insufficient budget and shortage of resources are some of the reasons why technology integration has not been successful in the some parts of the world (Butzin, 1992; Cafolla \& Knee, 1999; Dias, 1999; Office of Educational Technology [OET], 1995). Due to the huge potential of ICT impact on education, factors that influence the successful integration in school are studied in depth. Researches like Bennet (1996) and Fullan (1993) have recognized leadership as an important element in the school's success. With the vast amount of accessible technologies, school administrators could solve a wide range of educational problems, learning goals can be identified succinctly and ways can be determined by collaborating with others. A large range of student population could be catered to and a multitude of administrative task can be completed successfully (Office of Educational Technology [OET], 1995).

As mentioned by Brockmeier, Sermon, and Hope (2005), although teachers were identified early as playing an important role in the success of technology implementation, nevertheless the role of the school administrators were often overlooked. The following review of literature addresses the pivotal role played by the Principal together with his team of school administrators whom were collectively address as school administrators' in this study in the successful implementation of ICT tools in schools.

Becker (1993) contends that leadership is even more critical for the successful integration of ICT in schools today than it was before. According to Hope and Stakenas (1999), there are three roles played by the school Principal namely the role model, instructional leader and visionary role. Principals function as a role model when computer technology is applied to administrative and managerial task. As an instructional leader they facilitate teachers' integration of computers in Teaching and Learning. In the form of a visionary role they envisage a context for technology in school and are able to comprehend how learning can be restructured to empower teachers. 
The limited number of researches on Principal's relationship with computer technology obscures the abilities of the Principals and their potentials and it impedes an assessment of Principals' influence in achieving the promise of technology (Brockmeier et al., 2005). Brockmeier et al. (2005) conclude in their study indicating that achieving the promise of computer technology requires school administrators with vision and expertise. It is also highlighted in various studies that Principals need to achieve a threshold level of computer expertise before they are able to accomplish task and integrate computers successfully in teaching and learning.

School Principals have enormous responsibility for initiating and implementing school changes through the use of Information and communications technology (Schilller, 2003). Numerous researches find effective leadership as key and crucial ingredient for the success of any innovation in education (Bennet, 1996; Fullan, 1993). If one of our goals is to put technology into the hands of the students, we must help the teachers gain the necessary access, understanding and confidence. Administrative leadership is one of the best ways to bring teachers to this level of proficiency (Ritchie, 1996). There seems to be an apparent consensus that in the educational change literature, leadership is important but not confined to a single individual and this extends to leadership in education also.

The analysis of the 1998 Teaching and Learning Computing survey of more than 800 schools by (Anderson \& Dexter, 2005) conclude that 'although technology infrastructure is important for educational technology to become an integral part of a school, technology leadership is even more necessary. According to Anderson and Dexter (2005, p.73)

...”technology leadership has greater leverage on desired outcomes than does technology infrastructure and expenditures and further research in technology leadership is needed in the distributed research"...

Once the role as technology leader is assumed, the school administrators' have the crucial accountability for technology planning, financing, decision making, staff development and policy development and implementation (Gooden, 2006).

Even though the Principal is looked upon as the change facilitator, anyone can be the change facilitator as long as they can assume the role and responsibility that comes with it (Hall \& Hord, 2001). Finally, according to Gerald Bailey in 1996, Principals must also surround themselves with individuals who have the technology expertise to support their leadership.

The most current standards for school administrators regarding computer technology integration is the Technology Standards for School Administrators (International Society for Technology in Education, 2009). It is developed by the experts and professional organizations in the education technology field. These standards were put in place to assist school administrators in identifying core knowledge and technical skills needed to fulfill their leadership roles. The standards were categorized into five main sections namely:

1) Visionary leadership

2) Digital-Age Learning Culture.

3) Excellence in Professional Practice.

4) Systematic Improvement.

5) Digital Citizen.

Attempt should be made to for teachers to move beyond the use of computers for drill-and-practice into a more integrated approach to curriculum (Dias, 1999). As mentioned by Foley (1993), any approach to training in technology should be professional, peer-level and supported by adequate funding. One of the frequent cries and laments of teachers is the failure to provide adequate training and the push for technology integration with the constraint of time. As mentioned in Office of Educational Technology [OET] (1995) in order to integrate any form of technology innovation successfully into the curriculum, teachers need to be able to use and master the technological resources effectively in any teaching subjects.

In order to be effective, the various professional development programs need to have the capacity to meet the goals of the institution in question, the targeted results for the students, the level of sophistication of the teachers and the various technology available (CEO Forum on Educationa Report, 1999). Information Communications and Technology can heighten teaching efficiency through a multitude of pre-service training and programs that are pertinent and indispensable to the needs of the education system (GAID, 2009). The inclusion of such training as a pre-requisite for teachers enables them to have adequate content knowledge, a repertoire of teaching methodologies and strategies with a preparation of life-long learning. It is necessary to expose teachers to concurrent and new modern channels of information allowing self-learning to occur. 
In Malaysia a study conducted by University Science Malaysia (GAID, 2009) brought to light that successful diffusion of ICT into the classroom may be due to perceived administrative and technical support on the use of technology. In this study, a few issues were said to affect the integration effectiveness such as the existence of a sense of value of Information Communication and Technology's benefits and the expectation that its use will lead to success. Teachers who are dedicated, willing to learn, with a high level of resilience and determination to adapt their teaching methods to integrate technology into curriculum will always be the backbone of any successful implementation of Information Communications Technology based innovation. Theschool administrators should strive to provide a climate for teachers in school to grow and learn and develop such capacity.

A study conducted by UNESCO Bangkok in 2004 describes the following lessons learnt from six countries used in the study: teachers need to be trained on ICT-related skills within the classroom objectives to develop the skill to integrate use of Information Communications and Technology in teaching, training for teachers by more experienced peers of senior instructors from the Ministry of Education ensures that teachers follow the context of their workplace and training should be provided as a needs based and just-in time learning(Ng et al., 2006).

In a study carried out by Bauer and Kenton (2005) about technology integration in the classroom practice of 30 "tech-savvy” teachers who used computer technology in their instruction, even though the teachers were skilled in technology and innovative there was an inconsistence usage of technology in teaching and learning. This according to the study was due to the fact that students did not have sufficient time at the computers and teachers needed extra planning time for technology lesson.

Change forces acting in a school is internal and contextual. Each and every school is different in their response to the various Information Communication innovations. The challenge is to continuously maintain the momentum of change and innovations and to extend their achievement beyond established strengths (Yuen, Law, \& Wong, 2003). One of the parameters of innovation diffusion process as noted by Rogers (1995) is the social system. As such the diffusion of technologies may be inhibited by the micro culture existing in the organization or institution of question (Hodas, 1993). The schools' existing cultures and norms must be in tandem with introduced innovation in order to ensure acceptance. As mentioned by Maslowski (2001),

..."School culture can be defined as the basic assumptions, norms and values, and cultural artifacts that are shared by school members "...

In order to ensure the technology is well received and accepted by the school citizens, there should not be a mismatch between existing school cultures and norms and the introduced innovation.

The presence of a technical coordinator helps to reassure the administrative and pedagogical support for the teachers. The technical coordinator provides guidance and assists the teachers on teaching and learning problems, helps to ensure Information Communication and Technology resources are available when required, conducts training as needed based on the requirements of the teachers and also advices them on professional development (UNESCO, 2004). One of the barriers to the use of technology in classroom is the lack of on-site support.

According to Schoepp (2005), the act of integrating ICT into teaching and learning is a complex process and there will be a number of difficulties known as barriers. It is imperative that the obstruction is studied to provide a guidance to enhance technology adoption (Schoepp, 2005). It also reiterated by Al-Awani (2005) that identifying the underlying barriers may assist teachers to become successful technology adopters. British Educational Communications and Technology Agency (Becta) (2004) asserts that focusing on the barriers that particularly affect the practitioner in their specific roles would be helpful.

British Educational Communications and Technology Agency (Becta) (2004) classified barriers according to either those that relate to the individual ( teacher -lever barrier) which includes lack of time, lack of confidence and resistance to change or institutional (school-level barrier) which related to lack of effective training in solving technical problems and lack of access to resources.

Ertmer (1999) has categorized barriers into two namely extrinsic first order barrier and intrinsic second order barriers. Extrinsic first order barrier would be teachers' access time, support, available resources and training provided to teachers. The intrinsic second order barriers would be attitudes, beliefs, practices and resistance of the teachers.

Pelgrum (2001) sees it from a different perspective that is as two kinds of conditions: material and non-material. Material condition would include number of computers and number of computer software copies. Non-material condition would be insufficient ICT knowledge and skills, difficulty of integrating ICT in instruction and insufficient time. 


\subsection{Conceptual Framework}

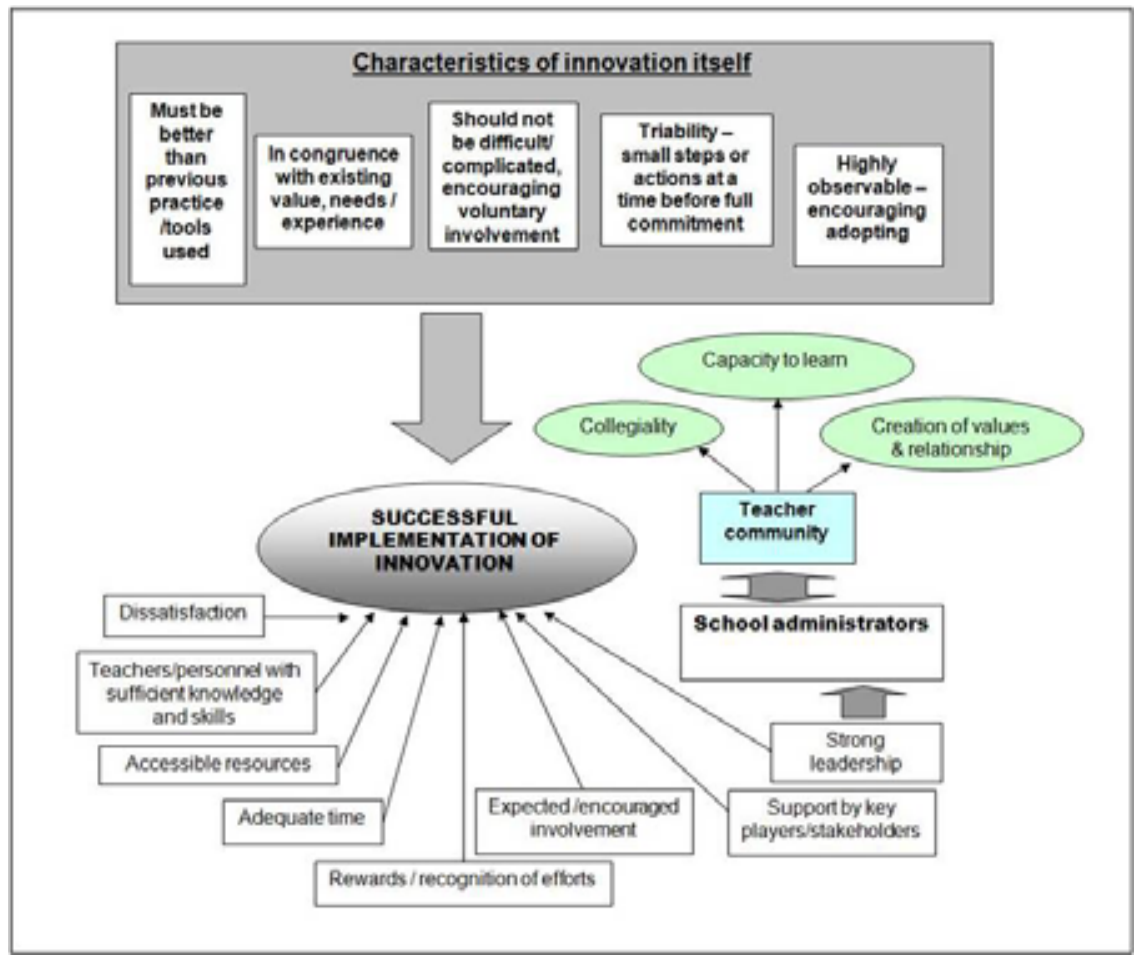

Figure 1. Conceptual framework based on Rogers Diffusion, Elly's condition of change and educational change by Fullan

\subsection{Materials and Methods}

In this study, qualitative research was employed to seek and to probe deeply into the research setting to obtain an in-depth understanding about the way things are and why they are that way (Gay, Mills, \& Airasian, 2009). Case study research in particular is a qualitative research approach in which the researcher focuses on a unit of study known as the bounded system (Gay et al., 2009). Yin (1994) went beyond the definition of a case to define case study research as a research strategy that is an all-encompassing method in covering design, data collection techniques and specific approaches to data analysis.

For the purposes of providing rich, in-depth and variation and descriptive data, the population selected in this educational context was a school in the district of Kulim, in a northern state of Malaysia. The aforementioned school is a Grade A school with a population of 2363 students and 142 staff including 134 teachers and 8 administrative staffs. It is situated within a $3 \mathrm{~km}$ radius of the Kulim town. Its students are predominantly single race and whose social status falls within a wide range of economic status.

The selection of the school is based on the fact that in order to supply rich set of data for this research required school that has already an ICT plan and a good infrastructure of computer hardware and software in place. The school under study has an efficient work culture and relationship among the large pool of number of staff is very professional. Computer usage is a necessity within the school vicinity using the Ministry of Education short messaging system. The school has implemented multitude of software's and portals to ease the burden of daily administrative task. Generation of examination grades are computerized with minimal data entry. Meetings are short and conducted on a regular basis. Memos are sent frequently and most of the teachers in the know of what is expected of them. They school has appointed two technology administrators one in the morning session and another in the evening session who are extremely well versed in both hardware and software and are able to provide on-site support if required.

The study is focused on the top administrative levels namely, the Principal, his senior assistant, the student affairs coordinator, the co-curricular coordinator, the 4 heads of department and a computer administrator. The participants selected are all from administrative level based on the assumption that the investigator wants to 
discover and understand and gain insight and therefore must select a sample from which the most can be learned (Gay et al., 2009).

The data collection method employed was in-depth individual interviews, observation of usage of computers and usage of computer labs, field notes were written after each interview and these again were triangulated with documents accessed from the schools files, school magazine, yearly teacher specification. Two interviews were conducted Interview1 and Interview2. All 9 participants were interviewed in Interview1. After analyzing the obtained data, a second interview, Interview2 was conducted with 4 of the participants to clarify some points and to gain a better understanding. The recorded interviews were later transcribed and analyzed.

\section{Analysis of Findings}

The matrix in Figure 2 summarizes an overview of factors that are mutually connected. It also highlights features found in this school which had directly or indirectly influenced the usage of ICT tools. Multiple times during the interview the participants mentioned the fact that the school had teachers who were willing to work together and share their knowledge to ensure completion of work. The Principal in many instances did not make decisions alone but consulted the ICT committee.

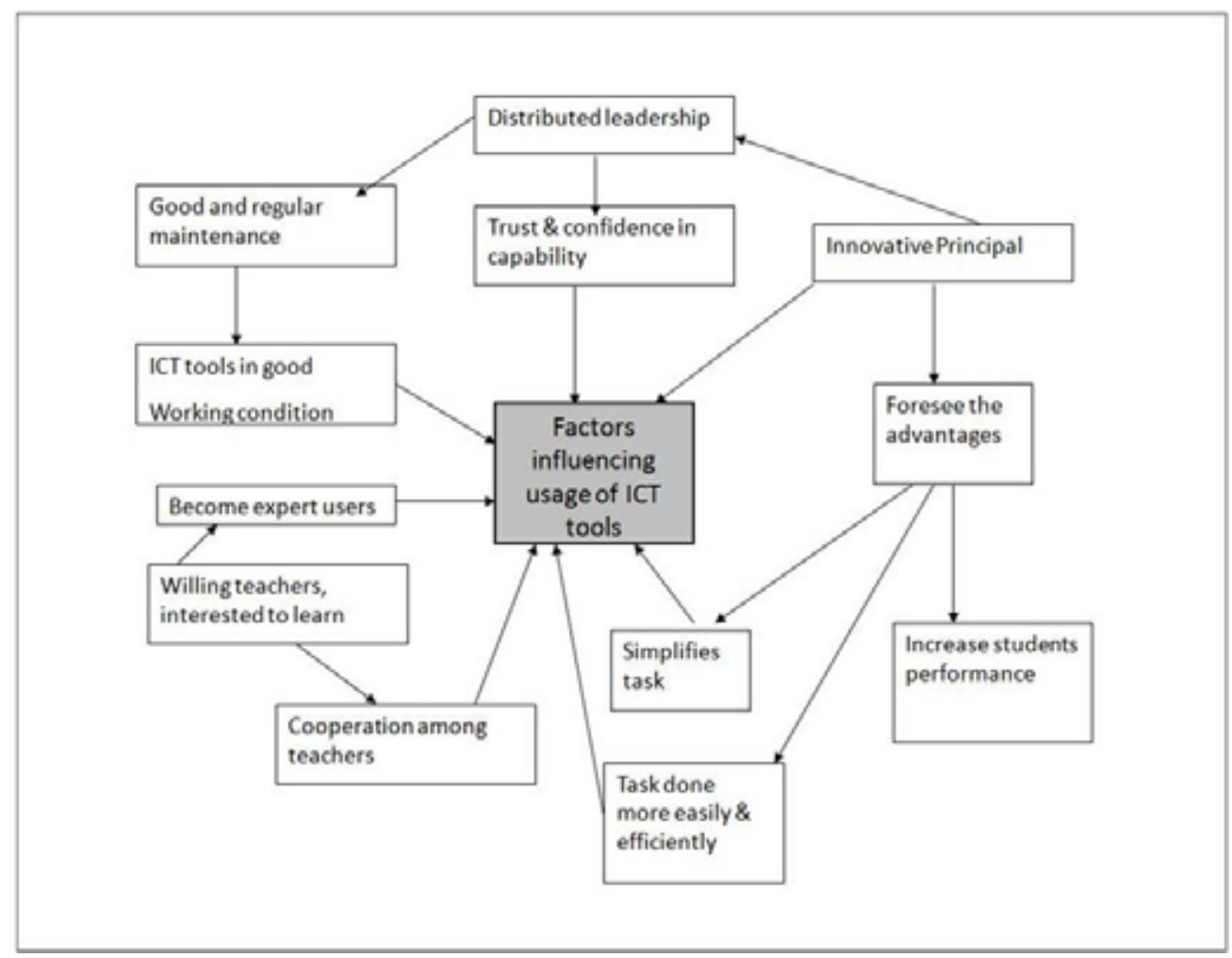

Figure 2. Factors influencing usage of ICT tools

The school administrators could foresee the advantages of using ICT tools and it was a shared vision and this shared vision was articulated to their respective staff in order to ensure proper usage of ICT be in administrative task or teaching and learning. Good and regular maintenance of facilities by teachers who are appointed technical experts ensures that the ICT tools are in good working conditions and hardware and software problems which occur frequently are resolved immediately to facilitate uninterrupted teaching and learning.

Within the pool of 134 teachers, they were many who took up learning how to use the various hardware and software willingly. This could be due to the fact the management in this school could foresee the advantages and took time and effort to disseminate information on a regular basis either through formal periodical meetings or through short messaging system (SMS) for quick results. Since the school is already connected the whole team of teachers through the smssekolah portal, any form of communication was straightforward either from Principal to teachers, senior assistant to teachers or among teachers themselves. Teacher could send instant messages to selected teachers too. Teachers in the school and new teachers are also constantly exposed on how to use these facilities. When these teachers are posted to the school, short training is given on the first week itself when they are given their smartcard. 
There were 12 personal computers placed in a special room for teachers to perform their day to day administrative tasks. There is a dedicated dot matrix printer for everyone's use. There is no restriction for usage and all of the personal computers are connected to the internet, schools e-learning portal and school's website. The centralized dedication of computers is a two pronged strategy and is very much in line with Rogers Diffusion of Innovation. In the school there were 4 technical experts, 2 new teachers who are being trained to take the job of the one senior technical administrator who is due to retire in April, 2 new teachers who were newly transferred to the school are already well versed in wireless wiring and network setting. Through these new teachers, the ICT committee recently purchased a few units wireless routers and repeaters and through their own effort had connected the whole school to have wireless access. This allows students as well as teachers free wireless access within the school vicinity.

One of the most highlighted factors during data collection was the good working condition of both hardware and software in the school. Even if the teachers bring in their own notebooks they could configure their equipment to have access to the schools network. The 4 computer experts are just a phone call away. Even sms are swiftly replied to. They make an effort to ensure problems are addressed expeditiously.

The decision to introduce new forms of either hardware or software is determined by either directive from the government or requirements set forth by the State Education Department or the District Level Educational Department. At times when school administrators attend meetings or courses, there exist mutual exchange of information casually or formally. At times the school administrators highlight keen observations of implementations that indicate improved teaching practices in other schools. In the desire to see similar happenings in the school, the concept or idea is usually discussed in the administrative meetings and put forward to the ICT committee.

As mentioned by Participant A2, the need arises when delays are obvious and cause impediment to flow of process and has an effect on overall administrative task. This may be due to unclear job specification, inability of the teachers to meet deadline. If such a case is frequent enough, then the working system is given a relook and adoption of technology to speed up process is thought of as an option. Better supervision is also quoted as way to introduce technology in schools. For example, would be monitoring of student and teacher attendance. With the existing EDMS system the absenteeism and late comer's statistics could be determined immediately after the school starts its session.

As mentioned by Schoepp (2005), there are a multitude of obstacles in the integration of ICT into teaching and learning known as barriers. Findings from this study indicate that school administrators point out the attitude of the teachers in their unwillingness to change, to accept any new changes. They are also said to be afraid to try. The reasons as quoted by some of the administrators are that they are not aware of the benefits the change could bring to the expedition of their work.

The teachers could be lacking proficiency in the adoption of new technology and this could reduce their competency as well as confidence to try and venture field of technology adoption. These are considered intrinsic second order barriers (Ertmer, 1999). For the first order barriers or extrinsic barrier could be the lack of time to access and learn. This in turn could be due to the full teaching hours that are experienced by the teachers. Two of the administrators cited the lack of facilities and booking hassle if the students are to be taken to the labs. To verify this fact, the researcher looked into the allocated time table.

Based on the findings of this research as mentioned by Rogers (1995), five major factors affecting the rate of adoption namely, relative advantage, compatibility, complexity, trialability and observability. In this research all the five were visible with some more prominent than others. The research findings indicate that school administrators are aware of the advantages in terms of simplified routine tasks due to adoption of technology, more efficient, better supervision and increased student performance. As far as the school administrators are concerned, their views and perceptions indicate positive cohesiveness with the various ICT tools used. They are able to share the vision of the principal on the foreseeable advantages of integrating ICT tools into teaching and learning. The changes were observable and these encouraged teachers to pick up new skill albeit at various levels but eventually innovation and changes were accepted as the norm in this school.

In terms of trialability, some implementation were taken in small steps, like the Headcount system which was build on scaffolding basis (built internally by the Computer Administrator), but some procurement like the EDMS system was a huge investment and requirement the teachers to adopt without question. Using Rogers Diffusion of Innovation alone could not explain the interrelationship and dynamic exchange that took place between the various components of this school. To enhance a further understanding, the researcher looked into namely Ely's Condition of Change and Fullan's Educational Change. 
Even if the findings of the research could not be generalized to other schools, but the combinations of factors that should be in place to support effective integration of ICT is identifiable and further research can be done to determine if the same results are observable in different context. The results of this study confirms the findings of Hall and Hord (2001) who supported the notion that besides the Principal , anyone can be a change facilitator as long as they can assume the role and responsibility that comes with it and the Principal need to be around people who have the technical expertise to support his leadership. In this study, the principal has his team of school administrators, four computer administrators and ICT committee who not only assist him in sourcing good hardware and software to realize his vision but also ensure the sustainability of new innovation in his school.

\section{Recommendations and Conclusion}

To further strengthen the findings of this research, some recommendations are made for future researchers:

a) It is clear and evident from the beginning that participants of this research were only administrators. Perspectives and perceptions of both teachers and students could be studied to determine relationship between these factors and factors cited by the school administrators.

b) Similar qualitative study could be conducted in other national schools that had other contextual differences. This would contribute to a richer and in-depth understanding of the various factors that motivate or inhibit the adoption and usage of ICT tools in schools.

It is my hope that the findings of this research would pave the way for a detailed understanding on the building of a stronger capacity for support on all aspects of learning from classroom to the central administrative office. It is hoped too, that policy makers would be made aware of how some inhibiting factors could be turned around by innovative and transforming leaders who could ensure the successful integration and usage of ICT tools in schools.

\section{References}

Al-Awani, A. (2005). Barriers to Integration Information Technology in Saudi Arabia Science Education. Doctoral dissertation, University of Kansas, Kansas.

Anderson, R., \& Dexter, S. (2005). School Technology Leadership: An empirical investigation of prevalence and effect. Educational Administration Quarterly, 41(1), 49-82.

Balsandran, A. R. (2006). Headmasters Reinforcement Behaviour and Teacher Performance. Seminar Kebangsaan Kepimpinan Instruksional Ke-2 IAB Cawangan Utara. Retrieved from www.iabu.moe.gov.my/Kertas8.pdf (February 20, 2011)

Bauer, J., \& Kenton, J. (2005). Technology Integration in the schools: Why it isn't happening. Journal of Technology \& Teacher Education, 13(4), 519-546.

Becker, H. J. (1993). Teaching with and about computers in secondary school. Communication of the Association for Computing Machinery, 36(5), 69-72.

Bennet, C. K. (1996). Schools, technology, and educational leadership: A Framework for change. NASSP Bulletin, 80(577), 57-65.

Benton Foundation. (2002). Great Expectation: Leveraging America's investment in educational technology. Washington, D.C.: Benton Foundation.

British Educational Communications and Technology Agency (Becta). (2004). A review of the research literature on barrier to the uptake of ICT by teachers. Retrieved from www.becta.org.uk (January 13, 2011)

Brockmeier, L. L., Sermon, J. M., \& Hope, W. C. (2005). Principals' relationship with computer technology. NASSP Bulletin, 89(643), 45-63.

Butzin, S. (1992). Integrating technology into classroom: Lessons from the project CHILD experience. Phi Delta Kappan, 74(4), 330-333.

Cafolla, R., \& Knee, R. (1999). Factors limiting technology integration in education: The leadership gap. In D. Willis (Ed.) Proceedings of the International Conference of the Society for Information Technology and Teacher Education, San Antonia, Texas March 22-25 1995 (pp 556-559).

CEO Forum on Educationa Report. (1999). The CEO Forum school technology and Readiness report. Professional Development: A Link to better learning: CEO Forum on Educational Report.

Dias, L. B. (1999). Integrating technology. Some things that you should know. Learning Leading with Technolgoy, 27(3), 10-12, 21.

Educational Development Plan for Malaysia (2001-2010). (2001). Generating Educational Excellence Through Collaboration Planning Executive Summary. 
Ertmer, P. (1999). Addressing first and second-order barrriers to change. Strategies for technology integration. Educational Technology Research and Development, 47(4), 47-61. http://dx.doi.org/10.1007/BF02299597

Foley, D. M. (1993). Restructuring with technology. A desegregation order created an opportunity to rebuild an old, overcrowded school into 21st - century learning centre. Principal, 72(3), 22-25.

Fullan, M. G. (1993). Change forces: Probing the depths of educational reform. London: Falmer Press.

GAID. (2009). White Paper - Information Communication and Technology (ICT) in Education for Development. Retrieved from http://unpan1.un.org/intradoc/groups/public/documents/gaid/unpan034975.pdf (January 10, 2011)

Gay, L. R., Mills, G. E., \& Airasian, P. (2009). Educational Research: Competenies for Analysis and Application (Ninth ed.). New Jersey: Pearson Education International.

Gooden, J. S. (2006). Computers, Use and Impact of. Encyclopedia of Educational Leadership and Administration: SAGE Publishers.

Hall, G., \& Hord, S. (2001). Implementing change. Patterns, principles, and portholes. Boston, MA: Allyn and Bacon.

Hodas, S. (1993). Technology refusal and the organisational culture of schools. Education Policy Analysis Archieves, 1(10). Retrieved from http://epaa.asu.edu/epaa/v1n10.html (February 13, 2011)

Hope, W. C., \& Stakenas, R. G. (1999). Leading the technology revolution: A new challenge for principals. In F.Kochan(Ed.). Paper presented at the Southern Regional Conference on Educational Leadership 1999 Yearbook: Leader for the 21st Century, Auburn, AL.

International Society for Technology in Education. (2009). National educational technology standards and performance indicators for campus administrators. Retrieved from http://iste.org/standards/nets-for-administrators.aspx (December 13, 2010)

Maslowski, R. (2001). School culture and school performance: An Explorative Study into Organizational Culture of Secondary Schools and their Effects. Twente: Twente University Press.

McCausland, H., Wache, D., \& Berk, M. (1999). Computer Literacy: an orientation strategy, its implementation and outcomes. Paper in progress HERDSA, Conerstone, What do we value in higher education? Melbourne.

Multimedia Development Corporation. (2005). The Smart School Roadmap 2005-2010. An Educational Odyssey. A consultative paper on the expansion of the Smart School initiative to all schools in Malaysia.

Ng, W. K., Miao, F. C., \& Lee, M. (2006). Capacity-building for ICT integration in education. Digital Review of Asia Pacific 2009-2010, 67-76.

Office of Educational Technology [OET]. (1995). Teachers and technology: Making the connection.

Pelgrum, W. J. (2001). Obstacles to the integration of ICT in education: results from a worldwide educational assessment. Computers \& Education, 37(2), 163-178. http://dx.doi.org/10.1016/S0360-1315(01)00045-8

Ritchie, D. (1996). The administrative role in the integration of technology. NASSP Bulletin, 80(582), 42.

Rogers, E. (1995). Diffusion of Innovations (4th ed.). New York: The Free Press.

Sammons, P. (1999). School Effectiveness. The Netherlands: Swetz and Zeitlinger.

Schilller, J. (2003). Working with ICT Perceptions of Australian principals. Journal of Educational Administration, 41(2), 171-182. http://dx.doi.org/10.1108/09578230310464675

Schoepp, K. (2005). Barrier to technology integration in a technology-rich environment. Learning and Teaching in Higher Education: Gulf Perspectives, 2(1), 1-24.

Tearle, P. (2004). A theoretical and instrumental framework for implementing change in the context of ICT in $\begin{array}{llll}\text { education. Cambridge Journal of 331-351. } & \text { Education, }\end{array}$ http://dx.doi.org/10.1080/0305764042000289956

UNESCO. (2004). Integrating ICT in Education. Lessons learned. A collective case study of Six Asian countries. Bangkok: UNESCO Asia and Pacific Regional Bureau for Education.

Yin, R. K. (1994). Case study research. Design and methods. Thousand Oaks, CA: SAGE Publisher.

Yuen, A. H. K., Law, N., \& Wong, K. C. (2003). ICT implementation and school leadership: Case studies of ICT integration in teaching and learning. Journal of Educational Administration, 41(2), 158-170. http://dx.doi.org/10.1108/09578230310464666 